\title{
Helmet Wearing and Traumatic Brain Injuries Among Motorcyclists in Cotonou
}

\author{
Iréti Fiacre Tidjani ${ }^{1,}$ ", Sègla Pascal Chigblo ${ }^{1}$, Valentin Houannou ${ }^{2}$, Thierry Alihonou ${ }^{3}$, \\ Eric Lawson ${ }^{1}$, Penance Agbélélé ${ }^{1}$, Soumaïla Madougou ${ }^{1}$, Aristote Hans-Moevi Akué1 \\ ${ }^{1}$ Department of Traumatology-Orthopedy, Centre National Hospitalier Universitaire Hubert Koutoukou Maga, Cotonou, Benin \\ ${ }^{2}$ Department of Anesthesia-Resuscitation, Centre National Hospitalier Universitaire Hubert Koutoukou Maga, Cotonou, Benin \\ ${ }^{3}$ Department of General Surgery, Centre Hospitalier Universitaire Départemental Ouémé/Plateau, Porto-Novo, Benin
}

Email address:

ireti89@hotmail.fr (I. F. Tidjani)

${ }^{*}$ Corresponding author

\section{To cite this article:}

Iréti Fiacre Tidjani, Sègla Pascal Chigblo, Valentin Houannou, Thierry Alihonou, Eric Lawson, Penance Agbélélé, Soumaïla Madougou, Aristote Hans-Moevi Akué. Helmet Wearing and Traumatic Brain Injuries Among Motorcyclists in Cotonou. Journal of Surgery.

Vol. 6, No. 3, 2018, pp. 73-77. doi: 10.11648/j.js.20180603.14

Received: April 28, 2018; Accepted: May 16, 2018; Published: June 8, 2018

\begin{abstract}
Background: traumatic brain injury is a real health problem, especially in low-income countries. The aim of this study was to assess the impact of helmet wearing on primary injuries in motorcycle trauma. Methods: this was a crosssectional study from $1^{\text {st }}$ January to $31^{\text {st }}$ December 2013. It covered all motorcycle users, admitted in emergency at Cotonou National Teaching Hospital, with a traumatic brain injury. Epidemiological variables and primary lesions were identified. Statistical analysis was performed with $\mathrm{Chi}^{2}$ and Fischer's tests; a p-value $\leq 0.05$ was considered statistically significant. Results: we collected 310 patients $(57.9 \%$ of traumatic brain injury), 11 of whom wore a helmet. They were predominantly male (male to female ratio $=7.6$ ), with a mean age of $33.2 \pm 10.9$ years. Craftsmen $(24.4 \%)$ were the most affected. The head trauma was often opened (172 cases / 299) in patients without helmet compared with 4 cases / 11 in patients with helmet ( $p=$ 0.001). Similarly, primary lesions were often more severe in patients without helmet, with a large number of primary lesions requiring surgery. Conclusion: helmet wearing significantly reduces the risk of serious primary injuries in motorcyclists in our context. Strict enforcement of mandatory helmet use should reduce the incidence of disabling injuries in our country.
\end{abstract}

Keywords: Motorcyclist, Helmet Wearing, Traumatic Brain Injury

\section{Introduction}

Traumatic Brain Injury (TBI) is a public health problem $[1,2]$. Their annual worldwide incidence is estimated at 10 million of cases, with a projection that they will be the $3^{\text {rd }}$ cause of morbidity in $2020[2,3]$. They mainly affect adolescents and young adults and occur mostly in low-andmiddle-income countries [1, 4]. In sub-Saharan Africa, the incidence is greater, with an incidence of $150-170$ per 100,000 compared with a global average of 106 per 100,000 [1]. These traumas are responsible for heavy socio-economic, functional and vital consequences $[1,2]$. In the United States of America, an estimation of 5.3 million persons are living with a disability resulting from traumatic brain injury [2]. In addition, the overall economic cost of these injuries was about $\$ 406$ billion in 2000 [5]. In Benin, the average direct cost of traumatic brain injury was $285.67 \pm 310.15$ Euros (56.97 - 2055.21 Euros) [6]. These traumas often involve unprotected motorcyclists [6], which could worsen the lesions encountered and increase their socio-economic costs. The aim of this study was to assess the impact of helmet wearing on primary injuries in traumatic brain injury among motorcyclists in Cotonou.

\section{Patients and Methods}

\subsection{Study Design and Population}

This was a cross-sectional study from $1^{\text {st }}$ January to $31^{\text {st }}$ December 2013. It covered all motorcyclists, at least 15 years old, with a traumatic brain injury whom were admitted to 
Cotonou National Teaching hospital, the level-1 referral hospital of Benin, a low-income country of West Africa. The health system of this country is third-level pyramid: the peripheral level (District or Communal health centers, supported by a regional referral hospital), the departmental level (departmental hospitals) and the national level (Cotonou National Teaching Hospital, and Mother and Child Teaching Hospital). In Benin, the rate of poverty was of $36.2 \%$. There is limited rate of social coverage and insurances take a longtime before giving a care provision. The victim's family outside the hospitalization fees must prepay all care services. The cost of a daily hospitalization is 9.90 Euros for a common ward. CT scan was asked according to Masters classification [7]. But patients had to carry out at least one x-ray of the skull considering the lack social security, the low socio-economic status of the population, and the cost of brain tomodensitometry which was about 122 Euros, that is twice of the guaranteed minimum wage in Benin. They also had to consent to participate to the study when there are able to speak and write. For teenagers, and uncounscious patients, their parents also gave their consent.

\subsection{Variables}

Dependent variable was helmet wearing. Independent variables were epidemiological and clinical. Epidemiologically, age, sex, occupation, level of education, circumstances of the trauma were identified. On the clinical side, we noted the severity of the traumatic brain injury at admission, if the trauma was opened or not, and primary lesions of the traumatic brain injury found clinically or with radiologic explorations. When the Glasgow coma scale was greater or equal to 13 , the traumatic brain injury was mild; Between 9 and 12, it was moderate and when it was less or equal to 8 , it was a severe traumatic brain injury $[8,9]$.

\subsection{Ethical Statement}

This survey was conducted in compliance with the protocol Good Clinical Practices and Declaration of Helsinki principles. Written informed consent to participate in the study after being informed about the purpose of study was given by all included patients. We also received parental permission and the written consent of the parents about teenagers, and uncounscious patients. Investigators guaranteed the total anonymity of the information derived from the research.

\subsection{Statistical Analysis}

Statistical analysis was performed with EPI Info 7.2. Qualitative variables are expressed as frequencies. Quantitative variables are expressed as means \pm standard deviation. The $\mathrm{Chi}^{2}$ test of Pearson or the exact Fischer's test as appropriate) were used to search correlation between the dependent variable and independent variables. A p-value $\leq$ 0.05 was considered statistically significant. The confidence interval was set at $95 \%$.

\section{Results}

\subsection{Epidemiological Characteristics}

We recruited 310 patients representing $57.9 \%$ of people with a traumatic brain injury received during this period. The mean age of the patients was $33.2 \pm 10.9$ years $(15-64$ years) and the 25-35 age group was the most affected with 120 cases $(38.7 \%)$. There were 274 men $(88.4 \%)$ and 36 women $(11.6 \%)$, a male to female ratio of 7.6. Regarding level of education, 95 patients $(30.6 \%)$ were non-educated; 85 patients $(27.4 \%), 72$ patients $(23.2 \%)$ were respectively primary and secondary level school; finally, 58 patients $(18.8 \%)$ had a university level. As far the profession is concerned craftsmen $(24.2 \%)$ and taxi-motorcycle drivers commonly called "Zemidjan" in our country (22.6\%) were the most concerned.

Traumatic circumstances were dominated by motorcycle against motorcycle collisions: 220 cases $(71.0 \%)$, followed by motorcycle falls (74 cases or $23.9 \%$ ) and motorcycle against car collisions (16 cases, 5.1\%). The victims were drivers of the motorcycle in 279 cases $(90.0 \%)$ and passengers in 31 cases $(10.0 \%)$.

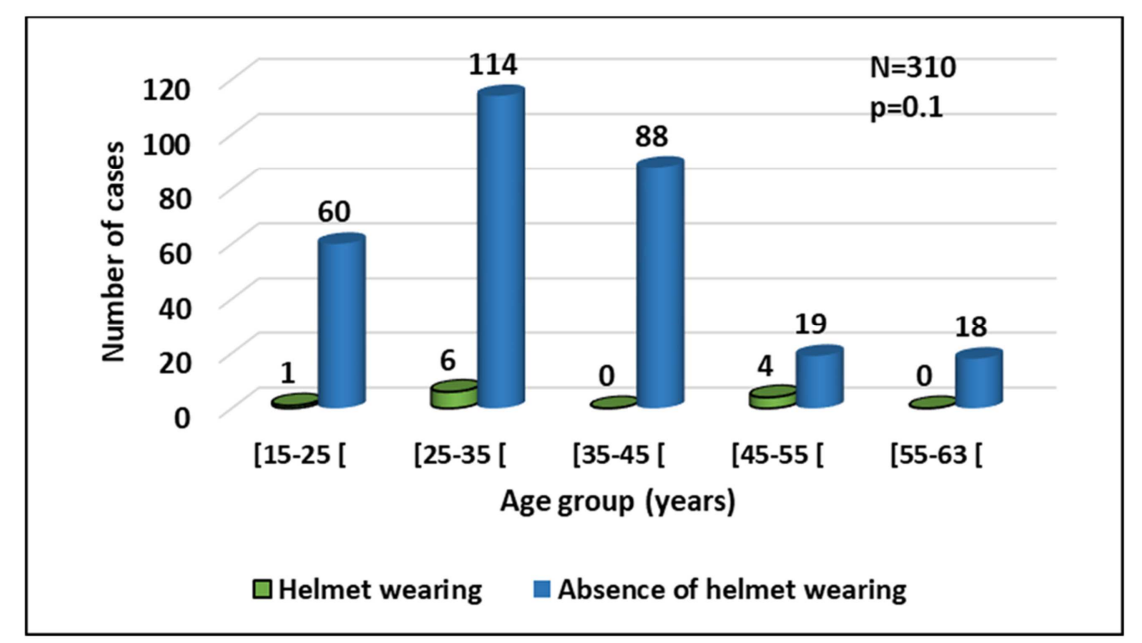

Figure 1. Distribution of patients by age group and wearing or not of a helmet. 
Eleven of the 310 patients wore a helmet, which means $3.5 \%$ of patients. Helmets were worn by subjects aged 25-35 and especially 45-55 years (figure 1), with no statistical association between age and helmet wearing $\left(\mathrm{p}=0.1 ; \mathrm{Chi}^{2}=7.7\right)$. The rate of helmet wearing was 3.3\% (9 cases / 274) for men and 5.6\% (2 cases / 36) for women without a statistical link between sex and helmet wearing $\left(\mathrm{p}=0.7, \mathrm{Chi}^{2}=0.6\right)$. Civil servant had the best observance of helmet wearing as shown in figure 2; however, there is no association between occupation and helmet use ( $p=$ $0.08, \mathrm{Chi}^{2}=9.8$ ). According to the position of the victims on the motorcycle, the drivers wore a helmet in $3.9 \%$ and none passenger was wearing a helmet.

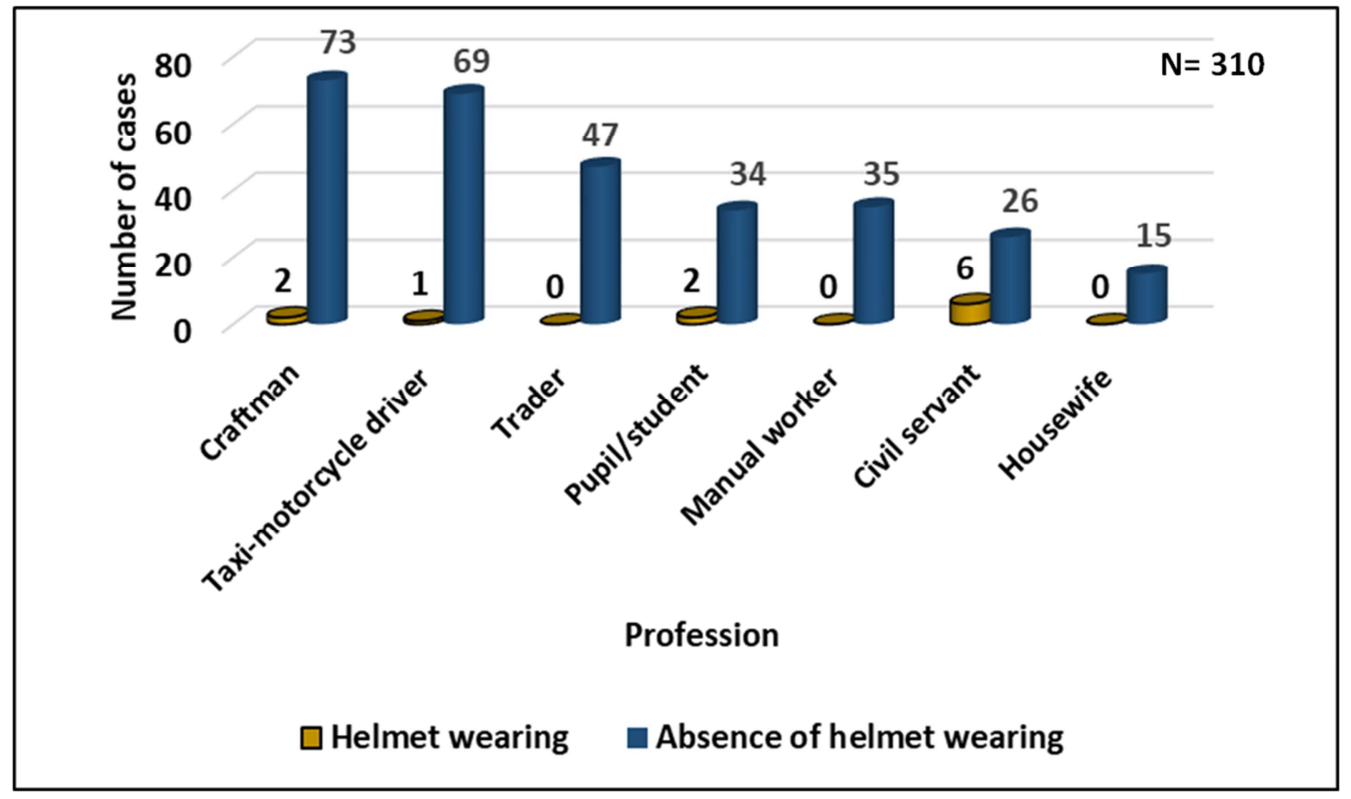

Figure 2. Distribution of patients by occupation and wearing or not of a helmet.

\subsection{Clinical Characteristics}

Most of traumatic brain injuries were mild (170 cases, or $54.8 \%$ ). Moderate and severe traumatic brain injuries were found in $22.9 \%$ and $22.3 \%$ of cases, respectively. Most severe traumatic brain injuries were found in patients who didn’t use helmet (figure 3), without statistical relationship between these two variables $\left(\mathrm{p}=0.4, \mathrm{chi}^{2}=3.9\right)$

The traumatic brain injury was opened in 174 cases $(56.1 \%)$ and closed in 136 cases $(43.9 \%)$. Among those with opened trauma, 4 patients $(0.6 \%)$ have used a helmet (figure 4$)$. There was a statistical relationship between helmet wearing and the traumatic brain injury opening $\left(\mathrm{p}=0.001 ; \mathrm{chi}^{2}=8.4\right)$.

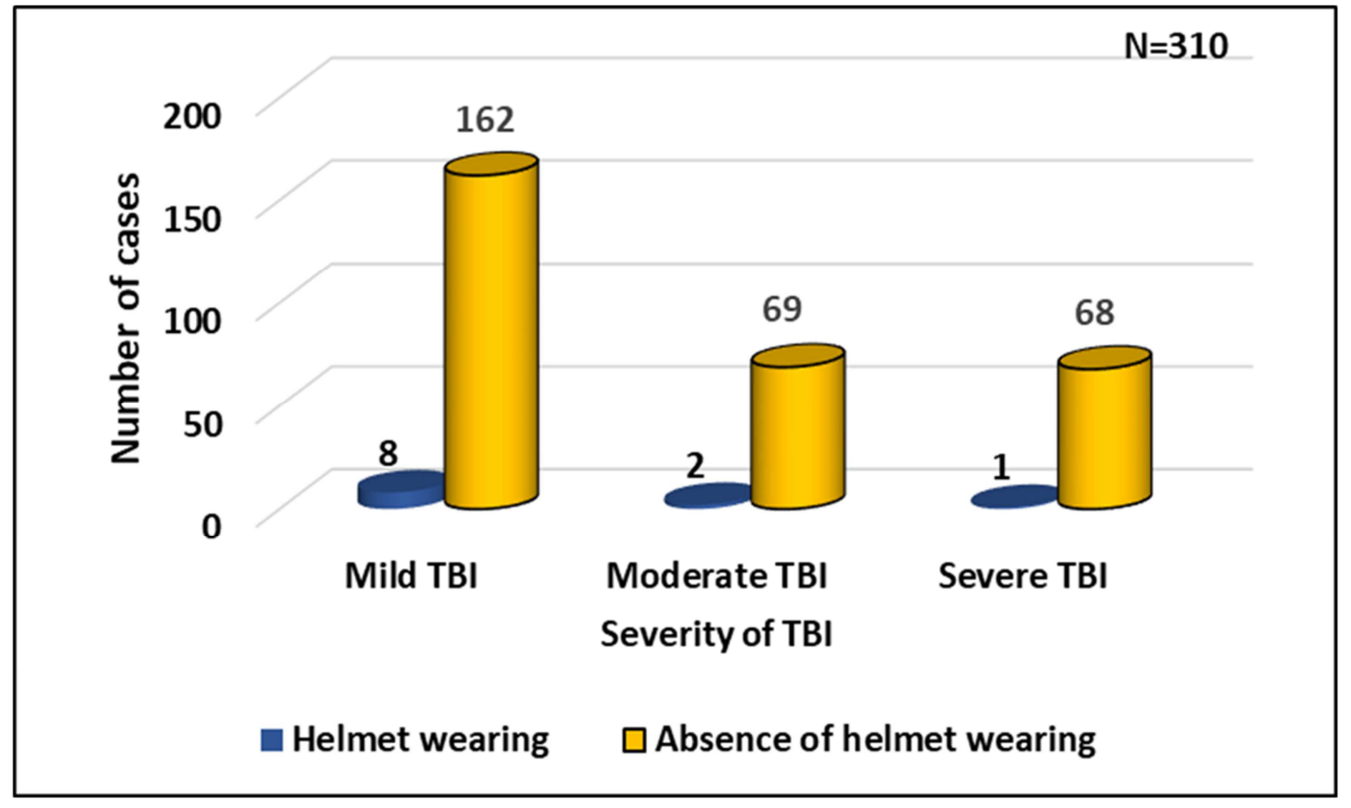

Figure 3. Distribution of patients according to the severity of the trauma brain injury and the wearing or not of helmet. 


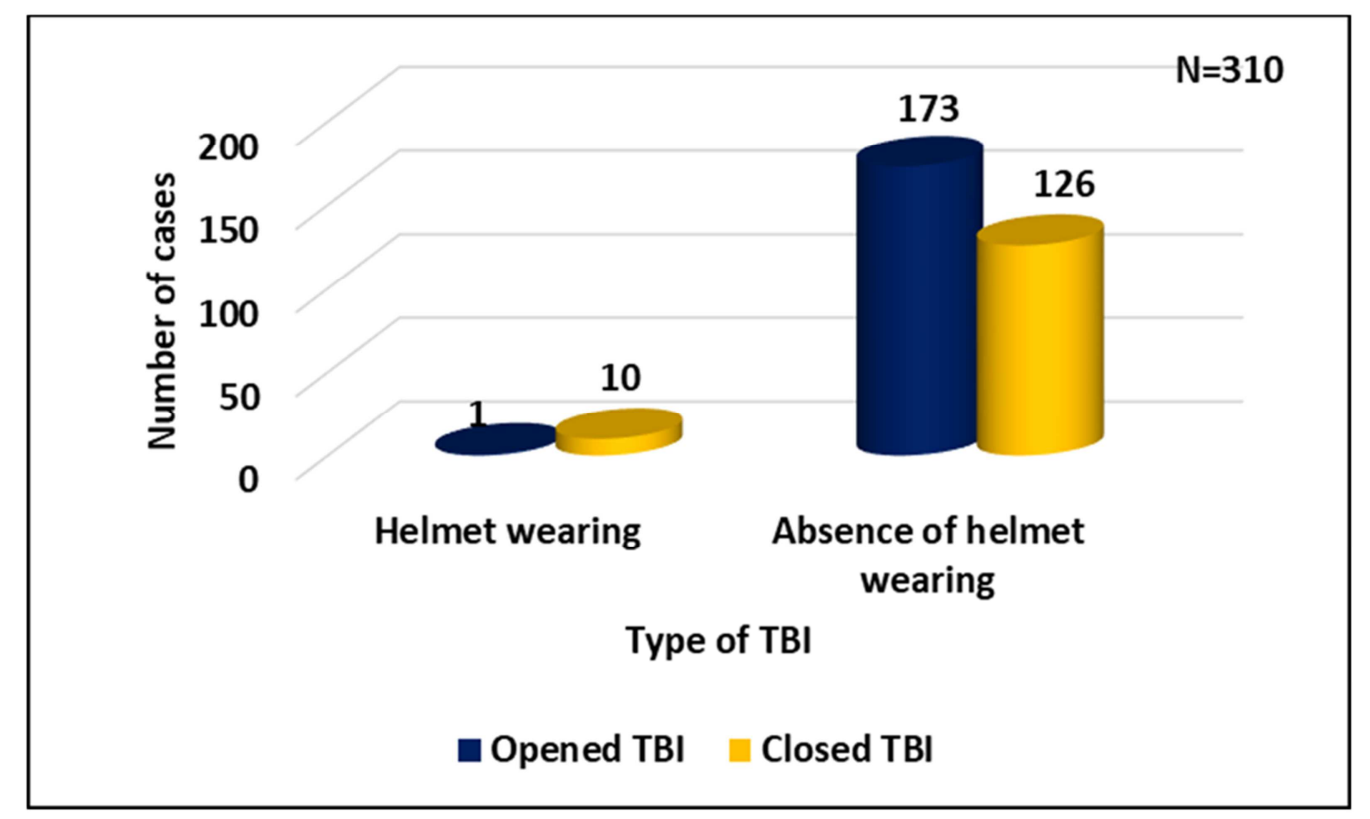

Figure 4. Distribution of patients according to the opening of the trauma and the wearing or not of helmet.

Primary lesions were dominated by scalp wounds (174 cases). Primary lesions requiring surgical treatment (scalp wounds, cranio-cerebral wounds, acute extradural and subdural hematomas, cranial bone fractures were more common in those without helmet (table 1). The extradural and subdural hematomas were found in 16 and 12 cases, respectively.

Table 1. Distribution of primary lesions by wearing or not wearing of a helmet.

\begin{tabular}{|c|c|c|c|c|c|}
\hline & Helmet wearing & Absence of helmet wearing & Total & P-value & OR [IC 95\%] \\
\hline Scalp wounds & 1 & 173 & 174 & 0.001 & $1.1[1.0-1.5]$ \\
\hline Cranio-cerebral wound & 5 & 31 & 36 & 0.0003 & $7.2[2.0-25.0]$ \\
\hline Fracture of cranial vault & 6 & 22 & 28 & $8.10^{-8}$ & $15.1[4.3-53.5]$ \\
\hline Fracture of cranial base & 3 & 19 & 22 & 0.03 & $5.5[1.3-22.5]$ \\
\hline Extradural hematoma & 2 & 14 & 16 & 0.001 & $13.7[3.5-53.1]$ \\
\hline Acute subdural hematoma & 3 & 9 & 12 & 0.006 & $12.1[2.7-53.3]$ \\
\hline Fracture of the facial bones & 1 & 9 & 10 & 0.3 & $3.2[0.4-27.9]$ \\
\hline Intraparenchymal hematoma & 1 & 7 & 8 & 0.2 & $4.2[0.5-37.2]$ \\
\hline Diffuse brain swelling & 2 & 4 & 6 & 0.02 & $16.4[2.6-101.4]$ \\
\hline Subarachnoid haemorrhage & 2 & 2 & 4 & 0.007 & $33[4.2-261.3]$ \\
\hline Diffuse axonal injury & 1 & 1 & 2 & 0.07 & $27.1[1.6-462.0]$ \\
\hline
\end{tabular}

\section{Discussion}

The aim of this study was to assess the impact of helmet wearing on primary injuries in traumatic brain injuries among motorcyclists at Cotonou. It presents a selection bias in the sense that some of the mild traumatic brain injuries are not included because they are not admitted in Cotonou National Teaching hospital. Similarly, the quality of the helmets used by the motorcyclists, who don't systematically buckle the straps of the helmet once worn, can't be stated with certainty. Finally, the speed of the motorcyclist during the accident should be taken into account for a better analysis of the results. However, this study, the first of its kind at the National Reference Center of Benin, is a starting point for more in-depth studies.

\subsection{Epidemiological Characteristics}

Several authors in the literature [10-14] have reported the young age and the male predominance found in this study. Traumatic brain injuries remain a major problem affecting the young subjects and thus handicaps the social and especially economic development of low-income countries such as ours. The compliance rate of helmet wearing was only $1.7 \%$ of the subjects aged of $15-25$ years. One might think that the risk-taking largely responsible for these traumas is related to the young age of the subjects, but the situation is not too different in the elderly. Indeed, if in subjects of 45-55 years the observance of the helmet wearing holds $21 \%$, there is nobody for the 55-63 years who wore a helmet. Furthermore, there was no statistical relationship between helmet use and patient age $(p=0.1)$. In fact, the reasons evocated to the non-wearing of helmet are often 
personal: the discomfort occasioned by the helmet, the difficulties of auditing the horn of other road users, mobility of the neck especially to see back, and in the women, the difficulties of wearing helmets on braids. These frequent subjective reasons show the lack of awareness of the usefulness of wearing helmet by the motorcyclists at Cotonou. This confirms the present study with only a $3.5 \%$ helmet wearing compliance.

\subsection{Clinical Characteristics}

Traumatic brain injuries were opened in 174 cases (56.1\%); Among these, only 1 patients $(0.6 \%)$ were wearing helmet and there was a statistical link between the wearing of helmet and the occurrence of these lesions $(p=0.01)$. Wearing helmet would therefore protect against skin lesions of the scalp during traumatic brain injuries.

Similarly, the primary lesions requiring surgical management concerned patients without a helmet with a strong statistical link between the occurrence of these lesions and the wearing of helmet (table 1). It confirms the fact that wearing a helmet would reduce the severity of primary injuries, and thus the morbidity and mortality associated with traumatic brain injuries, although the quality of the helmet depends on the type of helmet and the way it is worn [15].

\section{Conclusion}

Helmet wearing significantly reduces the risk of severe primary injuries in motorcyclists at Cotonou. Unfortunately, it is not systematic in the latter despite its compulsory character in our country. Implementation by the government of sanctions for non-compliance with mandatory helmet wearing should reduce the incidence of disabling traumatic brain injuries in our country.

\section{References}

[1] Tran TM, Fuller AT, Kiryabwire J, Mukasa J, Muhumuza M, Ssenyojo H, Haglund MM. Distribution and Characteristics of Severe Traumatic Brain Injury at Mulago National Referral Hospital in Uganda. World neurosurg 2015; 83: 269-77.

[2] Feigin VL, Theadom A, Barker-Collo S, Starkey NJ, McPherson K, Kahan M, et al. Incidence of traumatic brain injury in New Zealand: a population-based study Lancet Neurol 2013; 12: 53-64.

[3] The Lancet Neurology. Traumatic brain injury: time to end the silence. Lancet Neurol 2010; 9 (4): 331.

[4] Kiboi JG, Kitunguu PK, Angwenyi P, Mbuthia F, Sagina LS. Predictors of Functional Recovery in African Patients with Traumatic Intracranial Hematomas. World neurosurg 2011; 75: 586-91.

[5] Corso P, Finkelstein E, Miller T, Fiebelkorn I, Zaloshnja E. Incidence and lifetime costs of injuries in the United States. Inj Prev 2006; 12: 212-18.

[6] Hodé L, Madougou S, Fatigba HO, Hounnou P, Ebassa K, Hans Moevi AA, et al. The Direct Cost of Treatment of Traumatic Brain Injury in a Sub-Saharan African Country (Benin). World Neurosurg. 2017; 99:210-3.

[7] Masters SJ, McClean PM, Arcarese JS, Brown RF, Campbell JA, Freed HA, et al. Skull x-ray examinatons after head trauma. Recommendations by multidisciplinary panel and validation study. N Engl J Med. 1987; 316 (2): 84-91.

[8] Ledoux D, Piret S, Boveroux P, Bruno MA, Vanhaudenhuyse A, Damas P, et al. Les échelles d'évaluation des états de conscience altérée. Réanim 2008; 17: 695-701.

[9] Winkler AS, Tluway A, Slottje D, Schmutzhard E, Härtl R, the East African Neurosurgical Research Collaboration. The Pattern of Neurosurgical Disorders in Rural Northern Tanzania: A Prospective Hospital-Based Study. World Neurosurg. 2010; 73 (4):264-9.

[10] Agrawal A, Galwankar S, Kapil V, Coronado V, Basavaraju $\mathrm{SV}$, et al. Epidemiology and clinical characteristics of traumatic brain injuries in a rural setting in Maharashtra, India. 2007-2009. Int J Crit Illn Inj Sci. 2012; 2 (3): 167-71.

[11] Abou-Abbass H, Bahmad H, Ghandour H, Fares J, WazziMkahal R, Yacoub B, et al. Epidemiology and clinical characteristics of traumatic brain injury in Lebanon. Medicine 2016; 95:47.

[12] Fatigba $\mathrm{OH}$, Padonou J. Epidémiologie des traumatismes crânio-encéphaliques à Parakou. Afr J Neurol Sci. 2010; 29 (1): 25-33.

[13] Aenderl I, Gashaw T, Siebeck M, Mutschler W. Head injury-a neglected public health problem: a Four-month prospective study at Jimma University Specialized Hospital, Ethiopia. Ethiop J Health Sci. 2014; 24 (1): 27-34.

[14] Shekhar C, Gupta LN, Premsagar IC, Sinha M, Kishore J. An epidemiological study of traumatic brain injury cases in a trauma centre of New Delhi (India). J Emerg Trauma Shock. 2015; 8 (3): 131-9.

[15] Olsen CS, Thomas AM, Singleton M, Gaichas AM, Smith TJ, Smith GA. Motorcycle helmet effectiveness in reducing head, face and brain injuries by state and helmet law. Injury Epidemiology 2016; 3:8. 